\title{
The Main Statement Case: The Convergence of Business and Art in a New Venture
}

\author{
Brian George Nagy ${ }^{1} \&$ Domician Zahorjan ${ }^{2}$ \\ ${ }^{1}$ Assistant Professor of Management, Business Management and Administration Department, Foster College of \\ Business and Administration, Bradley University, USA \\ ${ }^{2}$ Bradley University, USA \\ Correspondence: Brian George Nagy, Assistant Professor of Management, Business Management and \\ Administration Department, Foster College of Business and Administration, Bradley University, USA. E-mail: \\ bnagy@fsmail.bradley.edu
}

Received: December 12, 2012

Accepted: December 27, $2012 \quad$ Online Published: January 8, 2013

doi:10.5430/jbar.v2n1p9

URL: http://dx.doi.org/10.5430/jbar.v2n1p9

\begin{abstract}
Danielle Auth and Matt Colgan founded The Main Statement in 2012. The venture began and remains a business that markets and sells unique locally produced gifts and accessories for women, men, kids, and home. The business attracts and caters to a very discerning clientele who appreciate sourcing, marketing, and selling local products made by artists and craftsmen. Although their passion is undeniable, the challenges they are facing are just as salient. Keys to future success include balancing the quality of the products offered within the business and the prices associated with them, as well as maintaining a commitment to only offer locally and regionally produced items. This case should be used in a pedagogical context and a practical context to discuss the challenges that arise from starting a business that is based on passion, not necessarily economic need.
\end{abstract}

Keywords: New ventures, Arts, Start-ups, Entrepreneurial partnerships, Entrepreneurial passion

\section{The foundation of a new venture}

In 2011 Danielle Auth (D. Auth, personal communication, November 15, 2012) was working for a multi-national retailer. Yet, she always had a passion and appreciation for locally manufactured, produced, and crafted products. She was particularly inspired to appreciate local craftsmen and artists after taking apparel merchandising and design classes before finishing her degree. Soon after graduating and after regularly visiting stores in several metropolitan areas of the United States (US), she realized starting up a new venture somewhere outside the large metropolitan areas within the US she had lived and visited may be a viable business opportunity. She thought helping undiscovered artists and craftsmen market their products in either a smaller metropolitan area or even a specific rural area may provide her and her business partner with a business opportunity.

Danielle's friend and soon-to-be business partner, Matt, always wanted to own a business to realize his aspiration and goals related to entrepreneurship. Although he studied business and sociology while completing his undergraduate coursework, in 2011, he was working for a small law firm in the same city where his soon-to-be business partner was employed. Similar to Danielle, he always had been interested in artistic products, especially those produced by local artists and craftsmen residing in the cities and towns where he lived at any point in his life.

\subsection{Recognition of the opportunity.}

Living and working in the southeast region of the US gave Danielle and Matt an appreciation for artistic communities. They saw many young people and artists producing and selling a wide range of hand-made products and forming cultural neighborhoods in certain districts of the cities around them. Given their interest in art, these districts and the unique cultures within them appealed to the nascent entrepreneurs very much. In many of these districts and neighborhoods, products that are mass-produced and sold globally through large multi-national retailers are not even offered for sale. Many of these districts were comprised of only locally owned stores and businesses offering locally and regionally produced items for sale.

These budding entrepreneurs recognized the many unique products artist produced as one-offs, and the value that is perceived from such products. For example, craftsmen who make a total of 10 to 20 pieces a year may be able to ask 
as much as $\$ 5,000$ to $\$ 10,000$ per piece, considering the dedication to the workmanship. These entrepreneurs realized the value in craftsmanship and art as well as the surrounding community that values art and craft.

Both these budding entrepreneurs determined they wanted to be a part of a community that resembled ones they had seen, but they were not sure how to earn a living while doing so. They considered many alternatives, like starting an organic yogurt store, or opening up a bakery. However, the idea of starting an art store selling local products emphasizing handmade production by local artists was the most interesting to them. Moreover, this idea seemed to make financial sense, at least in the beginning of the opportunity evaluation stage of creation of their nascent venture.

\subsection{Opportunity evaluation.}

Danielle and Matt enjoyed the time they spent working on their university degrees in a small metropolitan area, about 300 kilometers south of the city of Chicago. Although the area where their university is located is often considered lacking pizazz and an area that is slow to change with changes in society, a particular district in the area came to mind as a potential location to start a new venture. As of 2011, the area, known as "The Main Street Neighborhood" started to change rapidly, and many new businesses were quickly emerging. On a short visit back to the area, Danielle and Matt noticed this transformation and added the area to the list of viable locations for their new venture. Only a month after their short visit back to the area where they completed their undergraduate coursework, Danielle and Matt decided to start their venture in the area. They decided to become part of the growing community of business owners who demonstrated an appreciation for locally and regionally produced products. Though the community of business owners was small in size, the potential for growth in the district was obvious to the partners. They noted that since their departure to the southern region of the US, a costume design and rental business, a locally owned coffee shop, and a studio for artists had all started up operations in the area where, in the past, commercial activity had been nonexistent. In addition, the "Main Street Neighborhood" business area where they were shopping is located two kilometers from the north section of a mid-size metropolitan area of approximately 50,000 residents, and about one kilometer from a mid-size university community of approximately 6,000 students.

The nascent entrepreneurs researched the economic characteristics of the small metropolitan area of about 300,000 total residents. They found the area enjoyed relatively stable economic conditions in the past few years. This finding was important in the decision-making process related to where to locate the new venture. Also, the nascent entrepreneurs found that businesses marketing and selling locally produced art and fully customized and designed products were nearly non-existent in the small metropolitan area surrounding the "Main Street Neighborhood." Using market research, they both realized that high-income women 45 years old and above could possibly be their main target customer group in this niche market. Along with these potential customers, Danielle and Matt wanted to also target shoppers age 20-30 that resided in surrounding neighborhoods.

\subsection{Resource considerations.}

While working on their strategic plans and talking to some potential vendors, Danielle and Matt realized that the local artists and producers would be the most crucial factor of success. They purposely wanted to start their venture small, in terms of the scale of operations, for various reasons related to the flexibility of the venture and the culture of the "Main Street Neighborhood." These features of the organization were further necessitated by a few constraints that could potentially hinder the venture immediately after start-up, namely the lack of organizational legitimacy and the lack of start-up capital. Although these entrepreneurs consider themselves risk takers, they were planning to start only with their combined savings, without initially taking any substantial loans. They knew this lack of funding could limit their potential to attain legitimacy from key customers and local artists due to lack of advertising and lack of knowledge about the new business among potential customers and vendors. Regardless of the known risks of starting the business "small," from March 2011 to August 2011 Danielle and Matt developed a business plan, obtained the proper licensing and paperwork, and began networking extensively to start the venture the way they envisioned. After a half year of preparation, they were ready to start their new venture.

\section{Start-up of the Main Statement}

Operations at the new venture, The Main Statement, began in August 2012. The mission of the venture was and remains, "to market and sell unique locally produced gifts and accessories for women, men, kids, and home." The owners take pride in the fact that as of now, all hand-crafted merchandise sold by the Main Statement is made by local or regional producers. The inventory varies from ladies' accessories to ceramics, furniture to paintings. According to Danielle, The Main Statement should be where anyone could find something interesting and unique, produced in the local or regional area. When working with potential customers, Danielle emphasizes the vast amount 
of handcrafted inventory, and often notes that because an artist's or craftsmen's hands can never recreate the exact same thing, customers can be assured they are purchasing unique merchandise, impossible to duplicate. The importance of local community development goes hand-in-hand with the unique and locally produced items old in the Main Statement, differentiating the venture from its competitors. Presently, this focus on differentiating the business has allowed The Main Statement to break even, with very little retained earnings and very little earnings for the owner's efforts.

\subsection{Community development.}

Unique products need exceptional customer service. Danielle and Matt are aware of that and they are emphasizing the customer orientation of their business. The bottom line is to get to know the customers of Main Statement on a personal level and to help them find what they desire. Concentrating on the customers' shopping experiences and building loyal relationships with customers and vendors are the fundamental principles of The Main Statement and are the basis for future success. In addition to these principles, The Main Statement is part of a growing community of businesses in the Main Street Neighborhood. Owners consider themselves as part of a driving force behind the creation of something more than just a regular business district: the creation of a community with a sense of shared values and common ideas among business owners. These entrepreneurs emphasize the social aspect of their business and value added to society apart from economic profit whenever possible. This idea is the second most important principle in their business and is embodied in their daily business activities. In addition to economic profit, they want to create inspiration for others in the area, as well as provide an outlet for local artists and craftsmen to demonstrate their talents.

\subsection{Suppliers and consignment agreement.}

The fact that the venture was launched without any substantial funding from a bank has influenced the fundamental operations of The Main Statement. Since starting up operations, the owners have been unable to purchase much inventory. Almost all items sold in the Main Statement are offered based upon using a consignment agreement with the vendors. The consigners list their items at a fifty percent commission. So if the artists and craftsmen are displaying their products and items in The Main Statement the products and they are sold, The Main Statement takes a significant percentage of the revenue from the sales (i.e., fifty percent). Utilizing this business model has helped keep the costs of inventory down and also lowered the entrepreneurs' exposure of the risk of buying too much undesired inventory. As of the December 2012, only 3\% of the inventory in the Main Statement is owned by the business entity, with the rest being owned by consigning artists and craftsmen.

\section{Emerging challenges}

Until the Main Statement is properly established, these entrepreneurs are facing difficult challenges. In the near future, they realize they need to advertise in order to attain legitimacy within the industry and attract new vendors and customers. In addition, they need to increase customer satisfaction levels and increase the number of returning customers. The third challenge is to effectively manage all relationships with vendors and not succumb to the temptation of becoming just another retail outlet for cheaply made products disguised as hip or contemporary.

Another important challenge for the owners of Main Statement relates to market development strategies and efforts. Increasing The Main Statement's visibility and building its reputation seems to be of paramount importance now that the venture is in its infancy stage of development. This coincides with the expansion of The Main Statement's customer base. The customer base is important given the revenue and good will generated by returning customers. A related challenge relates to how to differentiate The Main Statement shopping experience from the average shopping experience derived from large retail stores. Creating the reputation that 'The Main Statement always offers something new, interesting and unique,' may increase the rate of returning customers.

As the business grows, it will become more difficult to manage inventory. In addition, the management of relationship with local artists and craftsmen serving as new and existing vendors may prove extremely difficult. Danielle and Matt have already begun to experience the irritation and problems stemming from individual vendors who have very little business knowledge. This has become a significant challenge when pricing items for sales. Many current vendors have been selling their products without the help of an organization like The Main Statement. Many vendors have no distinct way to value their products and account for the time, materials, and effort that have gone into producing them.

\section{Questions for discussion}

1) Discuss the process and methods utilized by Danielle and Matt before start-up. Comment on whether or not you may have done something differently. 
2) What were the situational factors that aligned to create The Main Statement?

3) What expectations do Danielle and Matt have of the vendors they utilize? Do you agree or disagree with this business model in this situation? Why or why not?

4) What do you think is the most significant challenge facing owners of The Main Statement as the venture enters its adolescent stage of development? Why? What suggestions would you make to avoid or overcome this challenge?

5) Do you feel this business model facilitates growth, given that utilizing such a model limits the owners in terms of supply chain participants and product offerings? If it hampers growth, what can be done to remedy this? If it facilitates growth, what should Danielle and Mark's next strategies be to grow the venture?

6) Do you think Danielle and Mark have forged a beneficial professional partnership with their suppliers? Why or why not?

\section{Teaching note for The Main Statement case}

\subsection{Description.}

This case describes some of the challenges of founding and operating a venture in the retail industry when the supply chain and products offered are purposely limited in an effort to gain a competitive advantage. The case chronicles the story of the two owners of The Main Statement, a business started in August 2012 in the midwestern region of The United States of America (USA). The case outlines and details the thoughts and decisions related to the entrepreneurship process before start-up, recent challenges during the infancy stage of organizational development, and the current challenges need to be overcome in the adolescent stage of organizational development. This case is appropriate for introductory-level courses related to entrepreneurship, small business management, and principles of management. The case is designed to be taught in a portion of one class period and is expected to require 30 minutes of outside preparation by students. The lessons learned from the case are thought to enhance the case participants' knowledge of the entrepreneurship process outlined in many of today's entrepreneurship textbooks, increase readers' level of knowledge about using a consignment method for product management, and to highlight the need for continual management of a new venture through its infancy and adolescent stages of development.

\subsection{Purpose.}

This case is intended for upper-level undergraduate students taking courses in entrepreneurship, small business management, or principles of management. The primary focus of this case is on the strategic choices made by the owners of this newly founded business. The case should be introduced once students have read material on opportunity recognition, opportunity evaluation, strategic management and business policy, supply chain management, and general management principles. The case is an example of two entrepreneurs' abilities to recognize an opportunity, analyze the risks and threats associated within the market, align resources in a bricolage fashion, and implement strategies associated with this new venture. The trials and experiences of the entrepreneurs are thought to be generalizable to many others seeking to found and manage new ventures in the retail industry and beyond. In addition, the entrepreneurs' relationships with the suppliers of The Main Statement are documented and illustrated in order to depict what can happen when new ventures and members of their supply chain face challenges during the nascent and post start-up stages of organizational development. The benefits and restrictions of these relationships should be used to promote discussion on the options entrepreneurs may encounter in their efforts to build reputable, legitimate, and profitable ventures while working to appease vendors who may not have vast amounts of business education and training.

\subsection{Research methodology and data collection.}

The authors of this case interviewed the founders of the business, in order to achieve an understanding of the business and the challenges stemming from owning it. The authors also spent several hours in the venture, making observations of the environment and the interactions between the owners and vendors, as well as the owners and customers. Employing the inductive approach, the themes of the case were realized and agreed upon after approximately fifty hours of observation, discussion, and transcription.

\subsection{Learning objectives.}

The purpose of this case is to introduce students to some decisions individuals who choose to start new ventures are faced with during the nascent, infancy, and adolescence stages of development. In addition, the case facilitates discussions on some of the challenges or opportunities that may lead to strategic choices related to them are made. Specific learning objectives include: 
1) Students will gain an improved understanding of the benefits and challenges associated with opening a new business as a partnership. With some intuition and reflection, students will gain an understanding of the benefits and consequences of two very similar individuals, like Danielle and Mark, partnering to become an entrepreneurial team.

2) Students will more fully understand that operating a business requires careful weighing of multiple options in order to make sound business decisions; and that each decision made will usually have both benefits and consequences.

3) Students will be encouraged to reflect on the unique nature of one type of business and the uniqueness of sourcing inventory on consignment. Given the sourcing method is used in small enterprises (e.g., The Main Statement), as well as large enterprises (e.g., many large retailers and food market businesses utilizing 'pay on scan' and 'scan-based trading' methods in vendor-buyer agreements), students will realize that the method can be used in profitable business settings to benefit both the vending organization and the buying organization.

4) Students will gain an improved understanding of the entrepreneurship process, pre-start up.

\subsection{Teaching strategies.}

Discussion of this case may need to be divided into two parts. In the first part, students should be asked to identify as many decisions made by the entrepreneurs as they are able. Students should be encouraged to identify both decisions that were explicitly mentioned in the case write-up as well as those implied. The primary purpose of this portion of the discussion is to identify topics to serve as bases for the second portion of the discussion. However, encouraging students to come up with as many decisions as possible will also help to highlight the point that many layers of decision-making exist. Each decision should be listed in chronological order so as to avoid confusion and to also facilitate later discussion of which decisions directly affected others.

Once the list is made, the second part of the discussion will focus on the individual choices made by the entrepreneurs. Individual decisions can be grouped into broader topics of discussion in order to avoid getting the discussion off track. Students should be asked about the positive and negative consequences of each decision that has been made by the entrepreneur, as well as possible alternatives and the impact these alternative decisions may have made.

Similarly, a discussion on the interpersonal and motivational topics within the case should be facilitated. However, rather than beginning with one list of potential decisions and choices, discussion participants should be asked for their thoughts on the positive and negative aspects of this partnership that have been formed to found this venture. Once this particular list is made, students should be asked if any aspects of Danielle and Matt's partnership may benefit from change and then asked to present alternatives. Students should be encouraged to provide justifications for suggested changes (or for leaving an issue the way it is) from a management perspective. Assigning small groups for discussion may be helpful at this point to allow for increased participation if the class is large.

\section{Additional Questions}

1.) Discuss the process and methods utilized by Danielle and Matt before start-up. Comment on whether or not you may have done something differently.

- A below average student will only state one or two of the steps that make up the entrepreneurship process.

- An average student will state all the steps taken.

- An above average student will state all the steps and explain the activities and tasks related to each.

2.) What were the situational factors that aligned to create The Main Statement?

- A below average student will state a couple obvious details included in the case like the entrepreneurs' interest in local and regional artistry and craftsmen produced products.

- An average student will state the four situational factors noted in the case.

- An above average student will go beyond the four factors stated in the case and note factors in the general business economy (e.g., rise in unemployment rates over the past few years in the USA) and a change in the culture of the United States (e.g., the recent rise in 'locavores - those only consuming products produced and sold by local or regional vendors, American's increased appreciation for 'market' and 'open market' style businesses, like those seen in most other parts of the world) have played roles in the creation of the new venture. 
3.) What expectations do Danielle and Matt have of the vendors they utilize? Do you agree or disagree with this business model in this situation? Why or why not?

- A below average student will simply state the entrepreneurs make vendors consign their products for sale, with no guarantee of sale.

- An average student will state the two expectations noted in the case: locally or regionally produced items are only available for sale, and that vendors must consign their products for sale. The student will also state a level of agreement without justifying the answer.

- An above average student will answer both questions and justify the answer to the second question with experiences or knowledge related to consignment-style vendor-buyer agreements.

4.) What do you think is the most significant challenge facing owners of The Main Statement as the venture enters its adolescent stage of development? Why? What suggestions would you make to avoid or overcome this challenge?

- A below average student will state a challenge or two, explicitly stated in the case (e.g., vendor relationships)

- An average student will state all the challenges explicitly stated in the case, mention one or two that are implied (e.g., this is a partnership that is between a woman and a man), and suggest some recommendations for overcoming a couple of the challenges.

- An above average student will state all the challenges stated in the case, mention more than two challenges that are implied (e.g., retailing to the masses may be a lot more profitable), and suggest recommendations for overcoming all the challenges stated.

5.) Do you feel this business model facilitates growth, given that utilizing such a model limits the owners in terms of supply chain participants and product offerings? If it hampers growth, what can be done to remedy this? If it facilitates growth, what should Danielle and Mark's next strategies be to grow the venture?

- The below average student will answer the first question in this series.

- The average student will answer both parts to this question but not justify the second answer given

- The above average student will answer the two questions and elaborate on the answers to both questions.

6.) Do you think Danielle and Mark have forged a beneficial professional partnership with their suppliers? Why or why not?

- The below average student will state an opinion and substantiate the opinion with a fact or two in the case.

- The average student will state an opinion and substantiate the opinion with numerous facts in the case.

- The above average student will state an opinion, substantiate the opinion with numerous facts in the case, and then elaborate on other examples of professional partnerships that demonstrate the benefits of forging them. 